TAO, Vol. 16, No. 5, 1045-1059, December 2005

\title{
Verification of the Suspected Tachia-tung Fault by Ground Penetrating Radar and Resistivity Image Profiling Methods
}

\author{
Chieh-Hou Yang ${ }^{1, *}$, Chun-Yi Yu ${ }^{1}$, Tai-Rong Guo ${ }^{2}$, Jeng-Yu Tsaur $^{3}$
}

(Manuscript received 22 April 2004, in final form 17 August 2005)

\begin{abstract}
A ground surface break may not be indicative of a fault. However, if the surface feature is supplemented with geophysical data, uncertainty can be reduced, as demonstrated here with three different electrical methods to verify the suspected Tachia-tung fault, near Tachia, Taiwan.

Ground penetration radar imaging reveals a prominent reflector which is offset vertically by about $2.6 \mathrm{~m}$ at depth about $2.3 \mathrm{~m}$ across the scarp. Schlumberger depth sounding exhibits a disrupted marker that links the loci of maximum apparent resistivity at greater depths.

Resistivity image profiling (RIP) surveys across the scarp yield either zones of low resistivity (two profiles) or disruption of high resistivity zones (one profile); those anomalies are suggestive of a low angle thrust fault.
\end{abstract}

(Key words: GPR, DC, Tachia-tung fault)

\section{INTRODUCTION}

Increasing population density and rapid industrial development in Taiwan require greater land use planning. Because Taiwan is located in the neotectonic belt along the western Pacific, active faults pose potential hazards to property and lives, as exemplified by the Chi-Chi earthquakes of magnitude 7.3 in 1999. Detecting and locating any possibly active fault in and around a proposed construction site is thus a key task in the evaluation of residential, industrial, or public works developments. This serious task falls upon geologists and geophysicists in Taiwan.

\footnotetext{
${ }^{1}$ Institute of Geoinformatics and Disaster Reduction Technology, Ching Yun University, Chung-Li, Taiwan, ROC

2 Institute of Geophysics, National Central University, Chung-Li, Taiwan, ROC

3 United Microelectronics Corporation

* Corresponding author address: Prof. Chieh-Hou Yang, Institute of Geoinformatics and Disaster Reduction Technology, Ching Yun University, Chung-Li, Taiwan, ROC; E-mail: yang@cyu.edu.tw
} 
Detection of an active fault, especially if buried, is frequently done by seismic methods (Byuner and Landa 1991; Zinni 1995). However, using either explosive or weight drop source for seismic exploration may cause actual or imaginary damage to a site or its surrounding infrastructure. Thus, seismic methods may not be deployable in urban areas. Geoelectric methods can provide a vital, non-destructive alternative, either as complementary or stand-alone methods. Good examples can be seen in Verma (1979), Honkura et al. (1985), Uri Basson et.al. (1994), Cai et al. (1996), Yang and Hung (1996), Unsworth et al. (1999) and Yang et al. (2002). With proper field design and data processing, the results yield a wealth of information about the nature of a fault (Yang et al. 2002). In addition to site-specific assessment, detailed mapping of active fault zones around a site is also of utmost importance for regional earthquake risk analysis. However, due to the fact that each geoelectrical method has different sounding depth and structural resolution power, joint or multiple interpretation of geoelectrical data may render better subsurface features than a single geoelectric method can perform (Tong and Yang 1990; Yang, et. al. 2002).

The newly developed automatic multi-electrodes (AME) system has been used successfully in resistivity image profiling (RIP) surveys on both land and water surfaces (Griffiths and Barker 1993; Yang and You 2002). RIP is a surveying technique developed to elucidate complex subsurface structures. High-definition pseudosections can be quickly obtained by dense sampling of resistivity variation at shallow depth. The method facilitates direct and inverse interpretation of subsurface 2-D resistivity distribution (Shima 1990; Loke and Barker 1996; Sasaki 1992). It is particularly suited for an urban area where lateral variation or geological structure is unsuitable for vertical electrical sounding (VES). The latter is also time consuming for data acquisition.

In order to understand and evaluate the feasibility of applying geoelectric methods to fault detection in Quaternary formations, direct current (DC) resistivity and ground penetrating radar (GPR) surveys were conducted on the Tachia-tung site located in western central Taiwan. The Tachia-tung fault has been the subject of much speculation and reports by many authors (Ku 1963; Shih et al. 1984, Cheng 1990; Tong and Yang 1990). The most definitive evidence of the fault's existence came from a DC-resistivity survey line (Cheng 1990; Tong and Yang 1990). This one-line result, however, does not provide enough information to determine salient features of the fault, in part, for lack of outcrop and well information. Additional and different geoelectrical methods such as RIP and GPR surveys are deployed, in this study, to better define the fault. Compared to the GPR survey, the RIP method has greater depth of penetration. It is also easy to obtain higher density of sounding data by RIP than by the conventional Schlumberger survey.

\section{GEOLOGICAL SETTING}

The Tachia-tung fault is located in western central Taiwan (Hsu and Chang 1979), between the Taan River on the north and Tachia Rivers on the south (Fig. 1). It extends from the eastern side of Tiee-shan, passes west of Tachia-tung, and ends east of Wei-shan (Lin 1957; $\mathrm{Ku}$ 1963; Tang 1969; Chen 1990). The total length of the fault is about $5 \mathrm{~km}$. It strikes northeast. 
Lin (1957) was the first to recognize the existence of the Tachia-tung fault through a linear scarp along the western side of the Holi terrace. The fault may be coeval with the Tachia fault. The area around the fault is covered by Pleistocene laterite and terrace deposits. The elevation differences across the fault between the "up" block on the northwest and the "down" block on the southeast range from a few meters to ten's of meters along the strike from south of Tachiatung to west of Neishuiwei (Fig. 1).

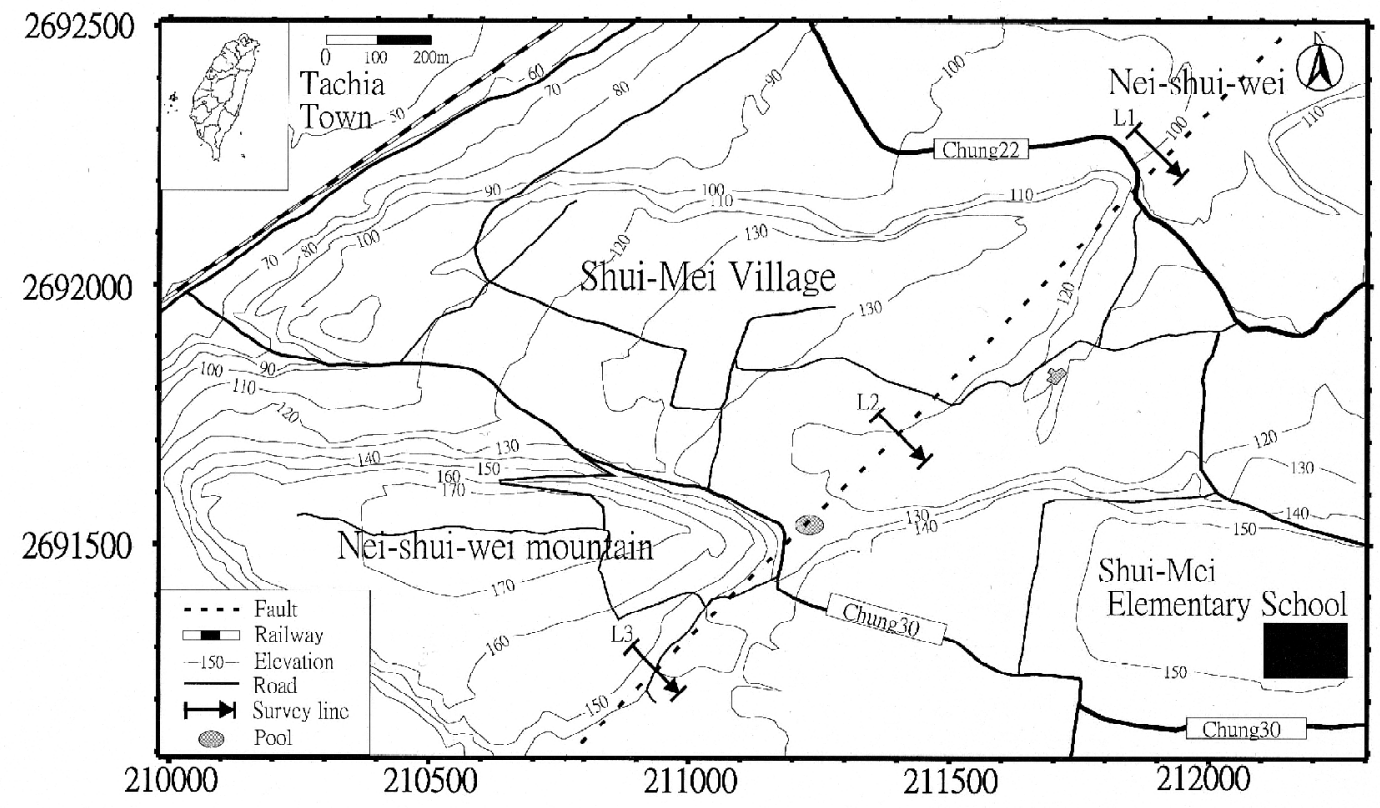

Fig. 1. Locality map of the Tachia-tung site. Numbers shown in the horizontal axis of locality map are in terms of $2^{\circ} \mathrm{TM}$.

The gravel layer atop the axis of the Houli anticline is thinner than that overlying the flanks. This unevenness suggests the gravel layer in the Houli tableland was deposited during or after the uplift of the Houli anticline. The layering in the apparent hanging wall on the NW side has a greater dip angle than that of the SE, which is nearly flat. The dip angles in the NW layers tend to increase toward the ground surface. This suggests that the subsurface layers had been compressed by lateral stress in the past. In addition, the altitude of the tableland between the Tachia fault and Tachia-tung fault is higher than that of its encircled formed horst. The Tachia fault is a northern extension of the Chinshui (or Changhua) fault, which has been recognized as an east-dipping thrust fault at shallow depth, and a normal fault at depth (Chang 1971; Hu 1985). In order to generate the horst between the two faults, the Tachia-tung fault was theorized to be a west-dipping thrust fault (Ku 1963). Studying the air-photos of terraces in northwestern Taiwan, $\mathrm{Ku}$ (1963) pointed out that the Taichia-tung fault extends from the 
study area northward to the Ta-Pin-Tan terrace and southward to the Ta-Do terrace. This long linear structure is not attributed to dragging by the Tachia faulting. Since the Tachia-tung fault is located a long distance from the north edge of the Taichung basin, the subsidence of the basin did not cause this linear feature. The shallow structure of the Tachia-tung fault indicates it is a NS thrust fault associated with the westward motion of the Philippine plate (Hsu and Chang 1979).

\section{PREVIOUS GEOELECTRIC STUDIES}

Most previous geoelectric surveys around the suspected Tachia-tung fault were carried out in 1989. The aim of the surveys was to evaluate the capability of the conventional DC resistivity and GPR measurements for detection and mapping of an active fault in a gravel covered area. The test site was selected for a linear scarp and step-like features associated with the suspected Tachia-tung fault.

\subsection{GPR Survey}

GPR lines were run over step-like topography which may be indicative of a fault scarp. The radar data were collected at two center frequencies: $100 \mathrm{MHz}$ and $50 \mathrm{MHz}$ using a PulseEKKO IV system. Transmitter and receiver were deployed perpendicularly to the survey line. Constant-offset profiling maintained a transmitter/receiver separation of $1 \mathrm{~m}$ or $2 \mathrm{~m}$, and station spacing was $0.5 \mathrm{~m}$ or $1 \mathrm{~m}$. Figures $2 \mathrm{a}$ and $3 \mathrm{a}$ are the same profile with different frequencies, $100 \mathrm{MHz}$ and $50 \mathrm{MHz}$ respectively. The final sections were obtained with the following data processing: DEVOW (i.e., removal of a low frequency noise), Drift removal (i.e., flatten and align the trace), Set time zero (i.e., establish the true zero time), Bandpass filter (i.e., the desired signal is enhanced at an expense of spectra outside the band), and F-K filter (i.e., frequency-wave number or velocity filtering). The final radargrams are displayed with equalizing all signals by a gain which is inversely proportional to the signal strength (Automatic Gain Control; AGC). The vertical axis is two-way travel time for radar wave in nanoseconds (ns), which can be converted to depth using an average vertical velocity of $0.06 \mathrm{~m} \mathrm{~ns}^{-1}$, which is obtained from velocity analysis of CMP (common middle point) radar data.

\subsection{DATA PRESENTATION}

Following the Surveying line L1, Figure 2a reveals a marker reflector offset vertically by $2.6 \mathrm{~m}$ across the fault trace. This offset is nearly equal to the relief across the scarp. Figure $2 \mathrm{~b}$ is a restoration of the radar section by aligning the ground surface on the two sides of the scarp to the same elevation. Figure 3a reveals two marker reflectors, the shallower reflector offset vertically by $2.6 \mathrm{~m}$ across the fault trace, as well as the deeper one offset vertically by $4.5 \mathrm{~m}$ across the fault trace. Figures $2 \mathrm{~b}$ and $3 \mathrm{~b}$ are the restoration of the radar sections by aligning the ground surface on the two sides of the scarp to the same elevation. The prominently discontinuous flat reflection events, shown in the central part of the radar sections where topographic 
high and low are present, were indicated by discontinuous radar responses. These discontinuous radar responses were the result of past subsurface dislocation.

Since most of the study site is a rice paddy field and has less alternation due to being farmed, the relative elevations of the ground surface across the two sides of the fault are likely preserved, i.e., the fault scarp has not been obliterated. That is why we correlate the reflectors by re-aligning the ground surface across the fault. Our approach is supplemented with the interpretation of DC survey results.

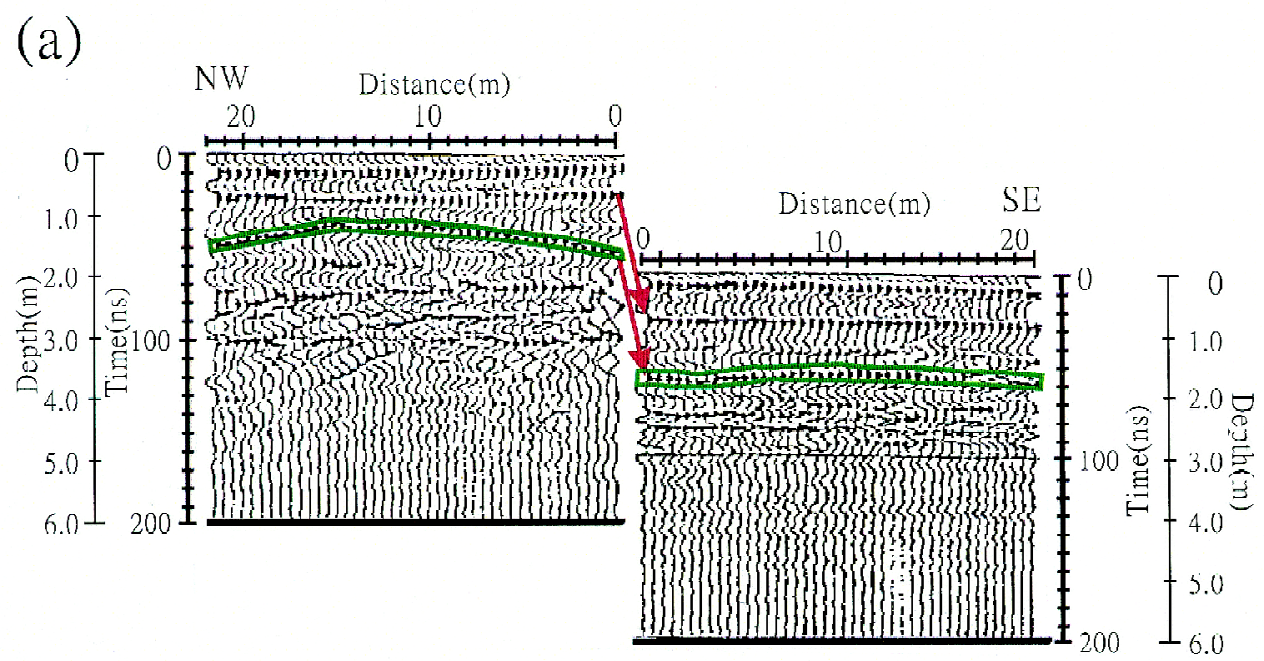

(b)

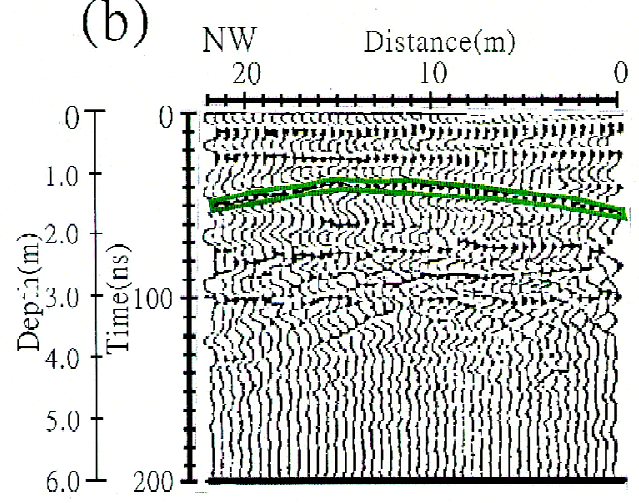



Fig. 2. (a) Radar section $100 \mathrm{MHz}$ perpendicular to the suspected fault trace near L1, (b) reconstructed electric stratigraphy for the radargrams shown in (a). 

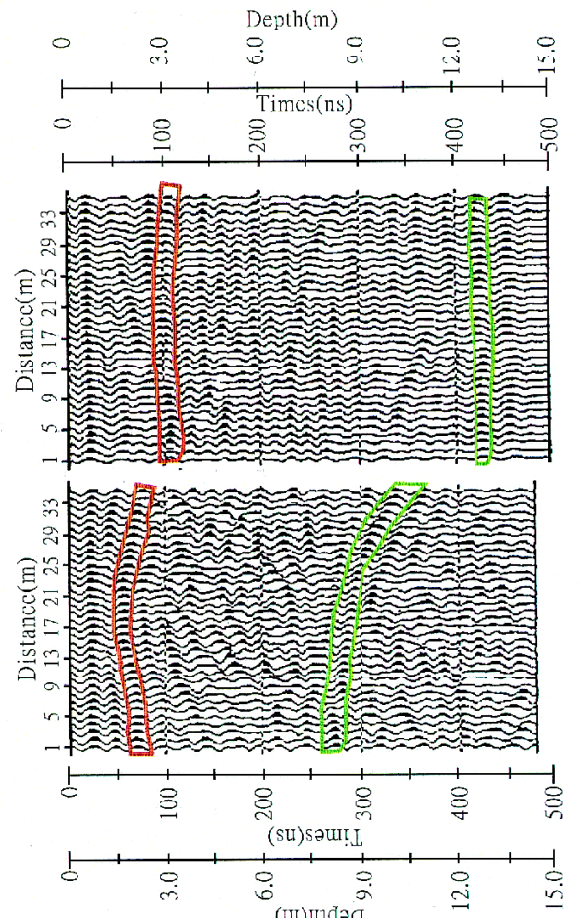


\subsection{SURVEY}

Figure 4a is a semi-log plot of Schlumberger VES curves for twelve sounding stations. The vertical axis is half-current electrode spacing in meters. The horizontal axis is the station number. The distance between each station is $20 \mathrm{~m}$. The VES stations follow the GPR survey line. DC resistivity data were collected using Scintrex TSQ-3 and IPR-10A (made in Canada). In order to meet the requirement of a 2-D assumption, the sounding spreads are in a NW to SE direction (i.e., perpendicular to the suspected fault trace) and have a length ranging from $380 \mathrm{~m}$ to $500 \mathrm{~m}$. As shown in Fig. 4a, an elevation difference of $2.5 \mathrm{~m}$ occurs between stations 34 and 35. Most of the apparent resistivity highs appear between 10 and $60 \mathrm{~m}$ in the pseudo-depth. For qualitative interpretation, we select the key bed to track the peak anomaly in each VES curve, as depicted by two dashed lines. The two lines disjoint between stations 34 and 35, coinciding with the suspected Tachia-tung fault trace. The pseudo-depth of the key bed in the NW side of the fault trace is less than that on the SE side. The upward tilting of the key beds toward station 34 is attributed to faulting. This tilting suggesting that the NW block thrusts to the east at low angle.

The faulted key bed is restored to its original position by aligning both sides of the ground surface to the same elevation (Fig. 4b). However, the dashed lines of Fig. $4 \mathrm{a}$ are not transferred to its initial state, which is shown by the dotted line. This indicates how the faulting might have caused the dotted lines shifting to the dashed line between stations 32 34.

Figure $4 \mathrm{c}$ shows the 2-D inversion results from the data shown in Fig. 4(a). The data shown in Fig. 4a were stitched together and used as the initial model for the 2-D inversion. The finite-element mesh used had 169 nodes in the horizontal direction and 18 nodes in the vertical direction. The subsurface was divided into 54 blocks. The final geoelectrical model shows 3 percent rms relative error after seven iterations. As demonstrated in Fig. 4c, the upper layer with higher resistivity is associated with the lateritic gravel of the tableland, while the lower resistivity layer under the gravel bed corresponds to the sandy clayey gravel of the Toukoshan Formation. The lateritic gravel bed has almost the same resistivity value on both sides of the fault. The gravel beds on both sides of the fault belong to the same lithologic unit, the inclined stratum formed prior to faulting. The DC result is comparable with that of GPR (light dashed line shown in Fig. 5). A faulting associated with the step-like topographic ground surface is verified.

\section{RESISTIVITY IMAGE PROFILING SURVEY}

Following the successful test survey using 2-D Schlumberger DC and GPR soundings to verify the Tachia-tung fault in 1989, three RIP surveys using a pole-pole technique and a newly developed RIP instrument were added in 1997. The aim of these RIP studies was to map the horizontal/vertical extension of the Tachia-tung fault.

RIP is a technique developed for investigating complex subsurface structure, especially at places where the use of standard DC resistivity sounding and other techniques are unsuitable (Griffiths and Barker 1993). The principle of this method is to measure the apparent resistivity by sequentially sweeping the quadrupoles - A, B (current electrodes) M, N (potential electrodes) 
(a)

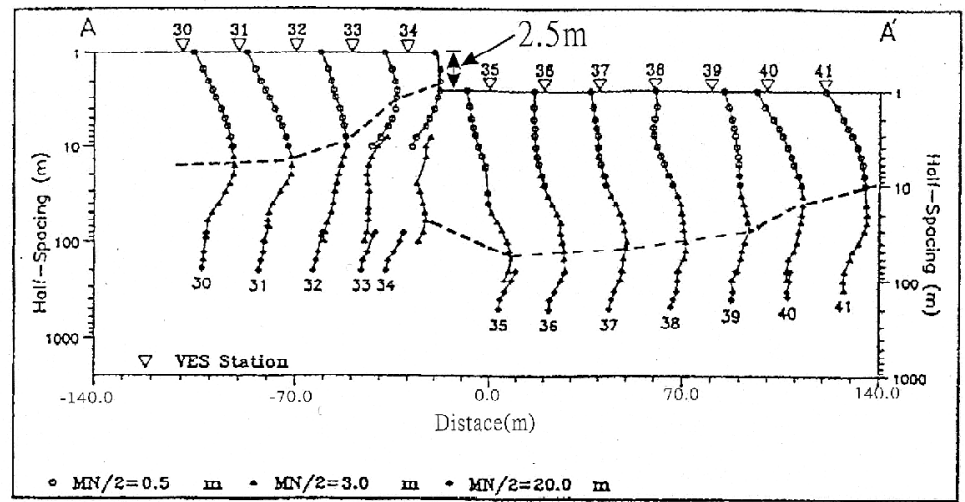

(b)

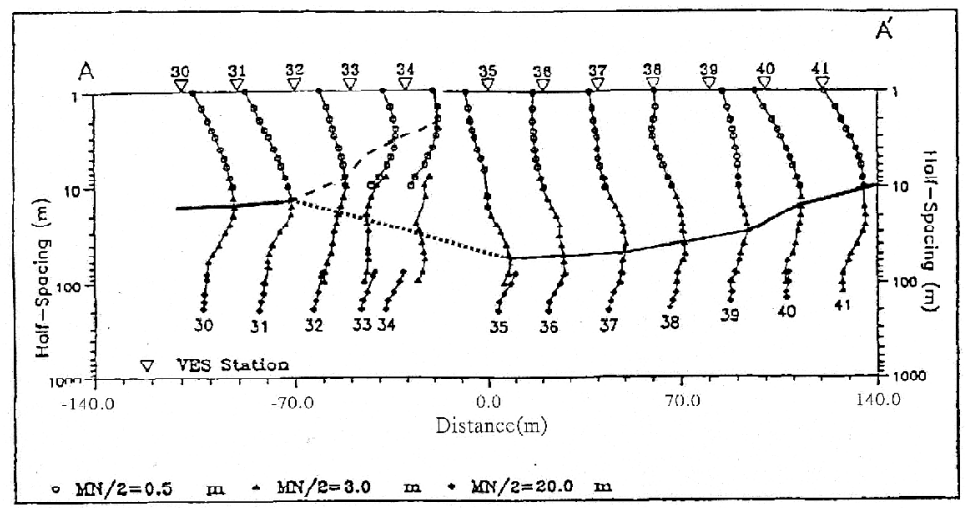

(c)

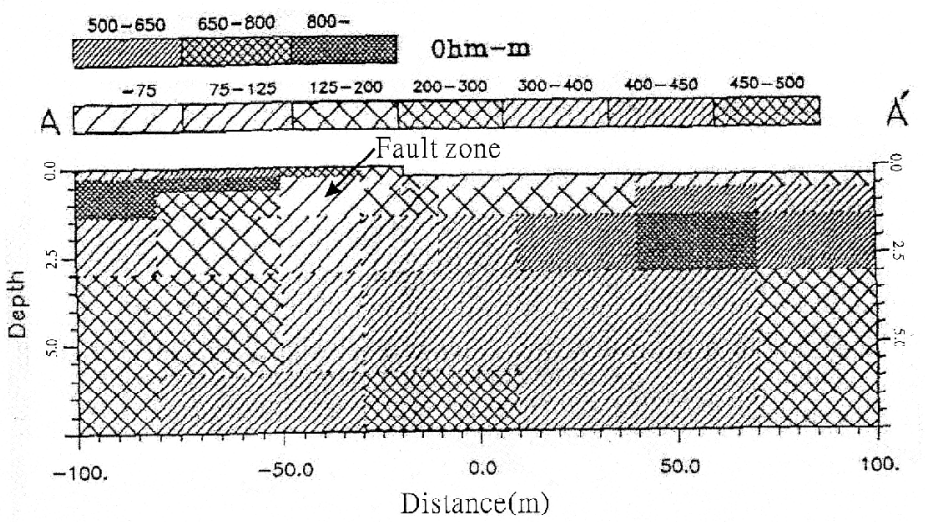

Fig. 4. (a) Schlumberger VES curves along the DC survey line L1. (b) VES reconstructed by aligning the ground surface across the scarp. (c) 2-D resistivity model for the data shown in (a). 


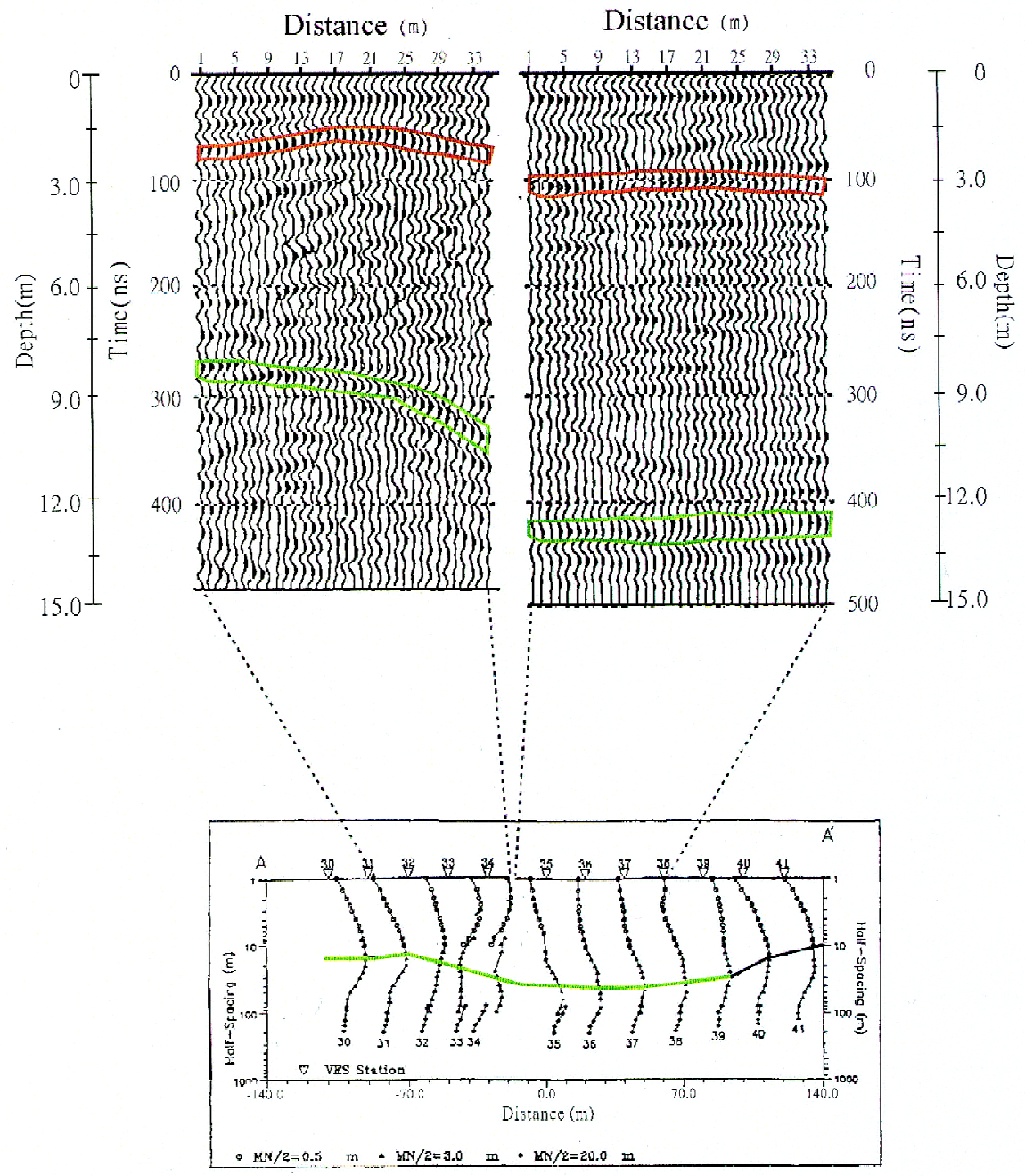

Fig. 5. Comparison of the VES result shown in Fig. 4 to the GPR results shown in Figs. 2 and 3.

- within the multi-electrode array. The method has the advantage of scanning and imaging the subsurface features at a rate faster than that of traditional DC methods. For interpretation, the apparent resistivity pseudosection data are inverted to provide an image model of the true resistivity.

Our electrode array is of a two-dimensional (2-D) pole-pole type. In field, we deployed multi-electrodes at constant separation. Each line had 32 electrodes with an inter-electrode (M, B) distance $4 \mathrm{~m}$. The stationary remote current electrode $\mathrm{A}$ and potential electrode $\mathrm{N}$ are placed at infinity, about $300 \mathrm{~m}$ or more than 20 times of the maximum separation between 
measured current (B) and potential electrodes (M), on the outer ends of the moving electrode array along a survey line (Loke 2000). If the remote electrodes cannot be placed at sufficiently large distance from the survey grid, a distance correction was made.

Pole-pole RIP data were collected with McOHM 21, manufactured by OYO, Japan. Figures 6, 7, and 8 depict the results along survey lines L1, L2, and L3 respectively, which are perpendicular to the suspected fault trace. The three are re-assembled in Fig. 9 for an overall

(a)

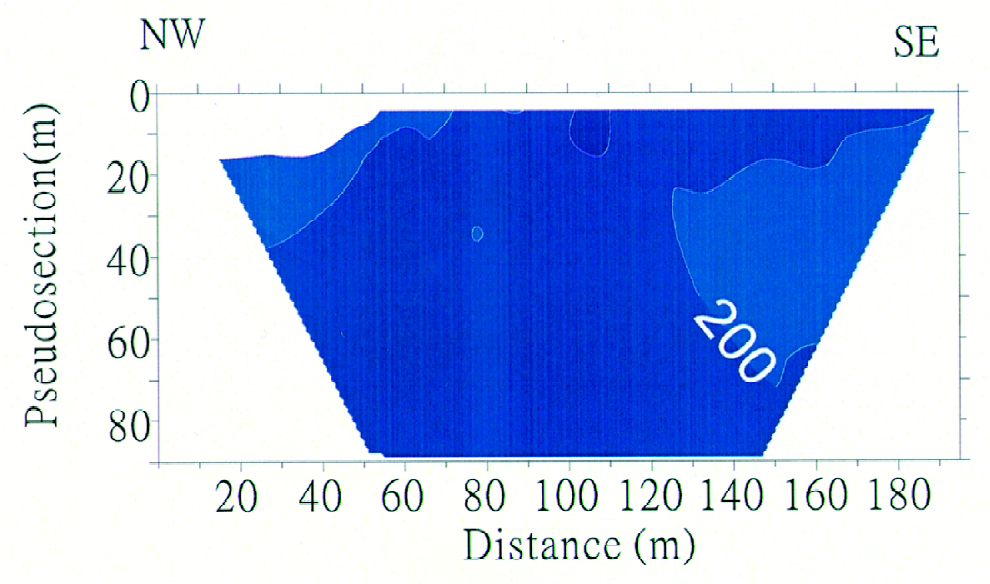

(b)
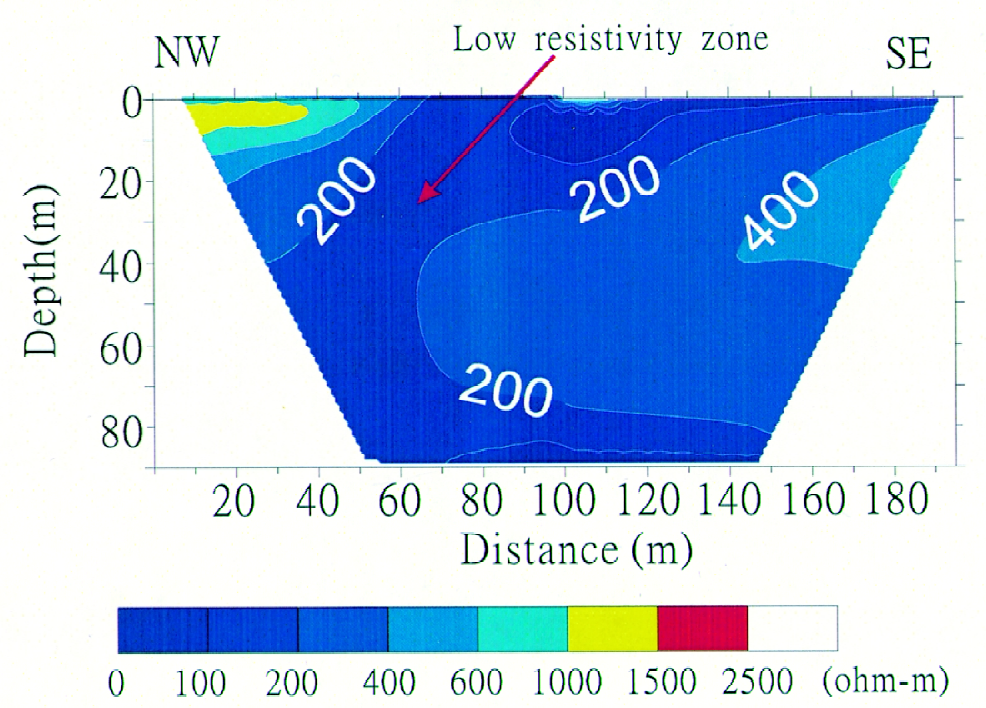

Fig. 6. (a) The apparent resistivity pseudosection of survey line L1. (b) The inversion result. 
(a)

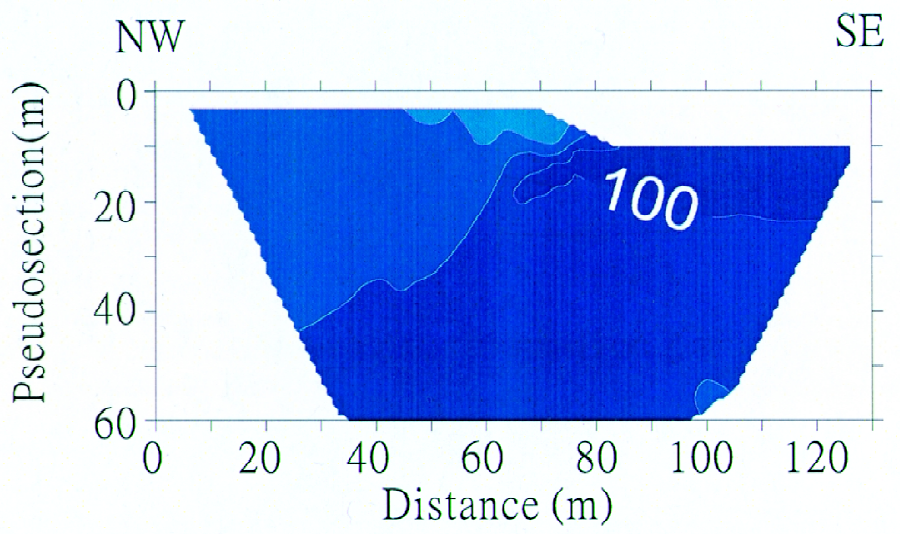

(b)
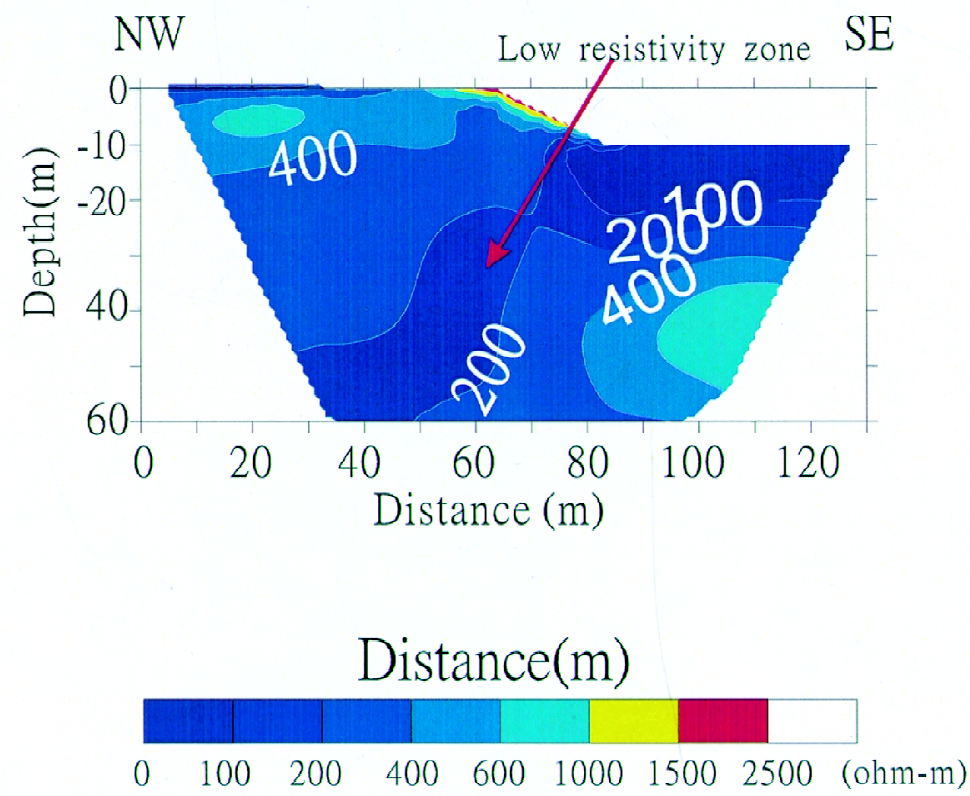

Fig. 7. (a) The apparent resistivity pseudosection of survey line L2. (b) The inversion result of the data shown in (a).

view of the results. Figure 6a shows the apparent resistivity section of Line L1. As shown in the figure, there is a NW dipping $200 \mathrm{ohm}-\mathrm{m}$ resistivity contour at the position of $55 \mathrm{~m}$ from the NW end of Line L1. This orientation of this resistivity contour may be related to the Tachia-tung fault trace. Figure $6 \mathrm{~b}$ is the inversion modeling result of Fig. 6a. The inverted 
(a)

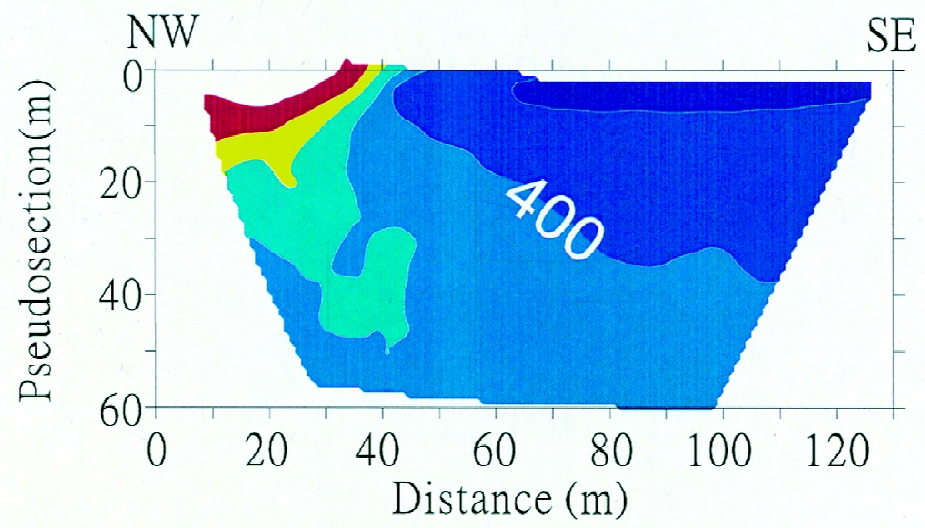

(b)

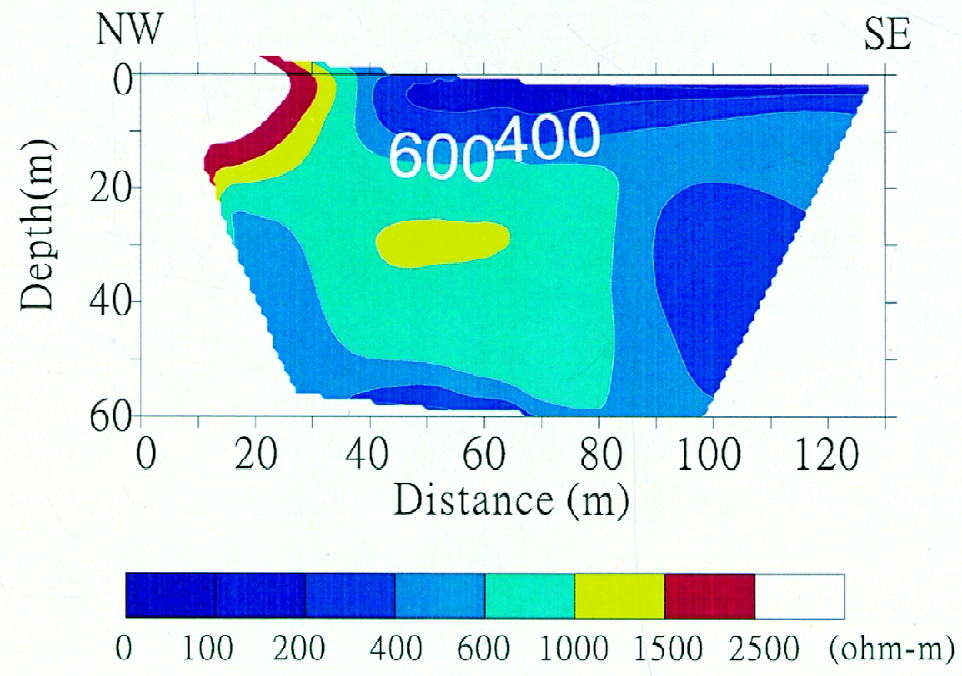

Fig. 8. (a) The apparent resistivity pseudosection of survey line L3. (b) The inversion result of the data shown in (a).

resistivity section indicates that a broad zone of low resistivity (less than $200 \mathrm{ohm}-\mathrm{m}$ ) dipping $\mathrm{NW} 30^{\circ}$. The resistivity zone in the NW side of this low resistivity zone is greater than that of the SE side. 

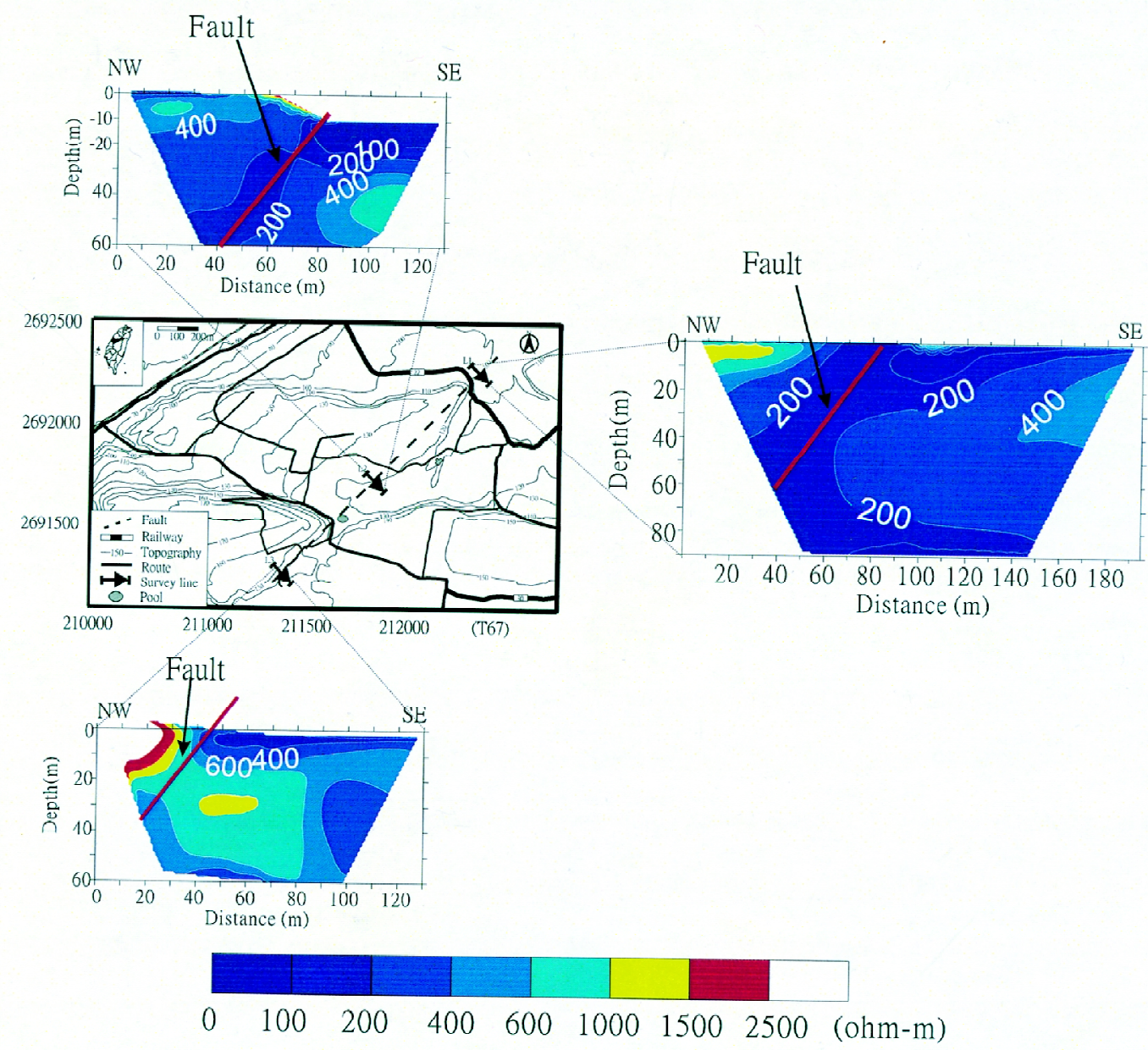

Fig. 9. The strike of the fault (dashed line) traced from the survey results of L1, L2 and L3.

Figure 7a shows the apparent resistivity pseudosection of Line L2, with a prominent $200 \mathrm{ohm}-\mathrm{m}$ resistivity contour dipping to NW, beginning at $70 \mathrm{~m}$ from the NW end of line L2. The hanging wall has a higher apparent resistivity (greater than $200 \mathrm{ohm}-\mathrm{m}$ ) than the footwall (200 ohm-m). This $200 \mathrm{ohm}-\mathrm{m}$ contour happens to begin (or end) near the scarp associated with the Tachia-tung fault trace. The model section indicates that a low reisitivity zone (100 200 ohm-m) dipping roughly $\mathrm{NW} 30^{\circ}$ is at $60 \mathrm{~m}$ from the NW end of Line L2. The resistivity in the NW side of this zone reaches over $1000 \mathrm{ohm}-\mathrm{m}$ while that of the SE side reaches a high value of less than $600 \mathrm{ohm}-\mathrm{m}$. The high resistivity zone at the upper left portion of the resistivity section may be associated with the gravel layer, while the lower resistivity zone to the right (SE direction) of the scarp is related to sand and shale. 
Along line L3, two high resistivity lenses (yellow) are disrupted near the scarp, and we interpret this disruption as caused by a NW dipping fault. The interpreted sections in Figs. 6, 7, and 8 are condensed in Fig. 9, along with the map of Fig.1. Based on the RIP results, a low angle of thrust fault is inferred as outlined by the NE-SW dashed line. It is noted that the resistivities of the layer along the fault trace increase from NE to SW. This increasing resistivity trend coincides with increasing elevation from NE to SW.

\section{CONCLUSIONS}

This study demonstrates an integrated application of GPR, conventional DC and RIP to analysis of a suspected fault in a gravel-covered area. GPR has high image resolution image but less depth of exploration. Traditional four collinear electrode DC surveys (such as Schlumberger VES) can sound deeper subsurface structures but the operation is time consuming. The pole-pole RIP survey is more efficient than conventional DC surveys and has greater depth penetration than GPR. A combination of the three different survey methods can complement one another for better characterization of the suspected Tachi-tung fault, which is now identified in this study as a SW-dipping low angle thrust fault.

Acknowledgements We are indebted to Professor Tier Lee (University of California at Riverside) for his valuable comments and helpful editorial.

\section{REFERENCES}

Byuner, I., and E. Landa, 1991: Fault interpretation from high-resolution seismic data in northern Neger, Israel. Geophysics, 56, 1064-1070.

Cai, J., G. A. McMechan, and M. A. Fisher, 1996: Application of ground-penetrating radar to investigation of near-surface fault properties in the San Francisco bay region. Bull. Seism. Soc. Am., 86, 1459-1470.

Chen, P. H., 1990, Electrostratigraphic study of the Quaternary Formations in Houli tableland. Proc. Geol. Soc. China, 31, 125-139.

Griffiths, D. H., and R. D. Barker, 1993: Two-dimensional resistivity imaging and modelling in areas of complex geology. J. Appl. Geophys., 29, 211-226.

Honkura, Y., A. M. Isikara, D. Kolcak, N. Orbay, S. Sipahioglu, N. Ohshiman, and T. Tanaka, 1985: Magnetic anomalies and low ground resistivity as possible indicators of active fault location: preliminary results of electric and magnetic observations from the western part of the North Anatolian Fault zone.J. Geomag. Geoelectr., 37, 169-187.

Hsu, T. L., and H. C. Chang, 1979: Quaternary faulting in Taiwan.Mem. Geol. Soc. China, 3, $155-165$.

Hu, C. C., 1985: Relation between deep structures and potential reservoirs from Ta-Tu Shan to Pa-Kua Shan, central Taiwan. Report of Inst. of Exploration and Production of Chinese Petrol. Corp. (in Chinese) 
Ku, C. C., 1963: Photogeologic study of terraces in north-western Taiwan. Proc. Geol. Soc. China, 6, 51-60.

Lin, C. C., 1957: Topography of Taiwan. Taiwan Sheng Tung Chih Kao, 1, 294. (in Chinese)

Loke, M. H., and R. D. Barker, 1996: Rapid least-squares inversion of apparent resistivity pseudosections by a quasi-Newton method. Geophys. prospecting, 44, 499-524.

Loke, M. H., 2000: Electrical imaging surveys for environmental and engineering studies, web site (www.geoelectrical.com).

Sasaki, Y., 1992: Resolution of resistivity tomography inferred from numerical simulation. Geophys. Prospecting, 40, 453-464.

Shih, T, T., K. H. Teng, J. C. Chang, C. D. Shih, G. S. Yang, and M. Y. Hsu, 1984: A geomorphological study of active fault in western and southern. Res. Report Dept. Geogr., Nat. Taiwan Normal Univ., 10, 49-94.

Shima, T., 1990: Two-dimensional automatic resistivity inversion technique using alpha centers. Geophys., 55, 682-694.

Tang, C. H., 1969: Photogeologic interpretation of the Miaoli area, Taiwan, with special reference to its geologic structures. Proc. Geol. Soc. China, 12, 11-19.

Tong, L. T., and C. H. Yang, 1990: Incorporation of topography into two-dimensional resistivity inversion. Geophys., 55, 354-361.

Unsworth, M., G. Egbert, and J. Booker, 1999: High-resolution electromagnetic imaging of the San Andreas fault in Central California. J. Geol., 104, 1131-1150.

Uri, B., E. Yehouda, A. Rivka, and B. A. Zvi, 1994: Detecting and mapping recent faults with a ground penetrating radar in the alluvial fans of the Arava valley, Israel. Proc. Fifth Int. Conf. on Ground Penetrating Radar, Kitchener, Canada, 777-788.

Verma, R. K., N. C. Bhuin, and C. V. Rao, 1979: Use of electrical resistivity methods for study of some faults in the Jharia coalfield, India. Geoexplor., 18, 201-220.

Yang, C. H., and Y. S. Hung, 1996: Investigation of active faults by ground penetrating radar along highway \#3, O-mei, northwestern Taiwan. J. Geol. Soc. China, 39, 591-603.

Yang, C. H., P. H. Cheng, J. I. You, and L. L. Tsai, 2002: Significant resistivity changes in the fault zone associated with the 1999 Chi-Chi earthquake, west-central Taiwan. Tectonophys., 350, 299-313.

Zinni, E. V., 1995: Subsurface fault detection using seismic data for hazardous-waste-injection well permitting: An example from St. John the Baptist Parish, Louisiana.Geophys., 60, $468-475$. 